\title{
Application of Progressive Collapse Analysis in a High-Rise Frame-Core Tube Structure
}

\author{
Hu Kai ${ }^{1, ~ *, ~ Q i ~ S a n l i n ~}{ }^{2}$, Qu Ge ${ }^{1}$, Jiang Li ${ }^{1}$, Lu Zheng ${ }^{3}$, Yang Shengsheng ${ }^{2}$ \\ ${ }^{1}$ China Shipbuilding NRDI Engineering Co., Ltd, Shanghai, China \\ ${ }^{2}$ CCCC Fourth Harbor Engineering Co., Ltd., Huangzhou, China \\ ${ }^{3}$ College of Civil Engineering, Tongji University, Shanghai, China

\section{Email address:} \\ whocannet@163.com (Hu Kai), SLQi730@163.com (Qi Sanlin), qu75675@163.com (Qu Ge), youlin_popo@126.com (Jiang Li), \\ luzheng111@tongji.edu.cn (Lu Zheng),yshengsheng@cccc4.com (Yang Shengsheng) \\ ${ }^{*}$ Corresponding author
}

\section{To cite this article:}

Hu Kai, Qi Sanlin, Qu Ge, Jiang Li, Lu Zheng, Yang Shengsheng. Application of Progressive Collapse Analysis in a High-Rise Frame-Core Tube Structure. American Journal of Civil Engineering. Vol. 4, No. 3, 2016, pp. 111-116. doi: 10.11648/j.ajce.20160403.18

Received: April 10, 2016; Accepted: May 9, 2016; Published: May 24, 2016

\begin{abstract}
Frame-core tube structure system is commonly adopted in high-rise office buildings and landmarks, which will cause a large range of damage and serious loss of life and property once the progressive collapse occurs. To analysis the progressive collapse resistance of a high-rise frame-core tube practical project, numerical simulation analysis based on alternate path method and explicit dynamics theory was conducted to study the dynamic response of the remain structure after removing a key member. In addition, large-scaled tests for the frame-core tube structure under static and dynamic loads were carried out to study the behavior and damage situation of the structure. The numerical simulation and test results proved that progressive collapse would not occur when local damages occurred in the bottom corner column, and the structure still has a good seismic performance under dynamic actions. And the feasibility and reliability of the selected numerical simulation method of progressive collapse analysis is proved according to the test results.
\end{abstract}

Keywords: Progressive Collapse Analysis, Frame-Core Tube, RC Structure, Alternate Path Method, Numerical Analysis, Collapse Test

\section{Introduction}

Security issues are the primary problems of structural design, and many engineering accidents happened because of the progressive collapse caused by incidental loads. In recent years, such kind of accidents emerge in endlessly, such as the collapse in the terrorist attacks of 11 September 2001, the "Loudoadao" event in shanghai, as well as the "Loucuicui" event in Fenghua, Zhejiang Province, which once occurs, would cause a large range of damage and serious loss of life and property, increase the later repair difficulty of the buildings, or even lead to the structure completely discarded.

In order to effectively avoid such collapse accidents, many researches on progressive collapse resistance of RC structures have been carried out. The collapse mechanism of a plane frame structure by pseudo-static collapsed destruction test and numerical simulation analysis with LS-DYNA software [1]. Dynamic responses of frame structures with different members removed respectively were studied based on OpenSees platform [2-3]. Force mechanisms of frame structure with bottom columns removed was studied by test [4-5]. And the collapse process of a high-rise frame-core structure under seismic actions was analyzed use numerical simulation methods with TECS program [6]. According to the current studies of progressive collapse analysis of $\mathrm{RC}$ structures, continuous collapse resistance analysis based on numerical simulations and tests is feasible, and the reliability was verified in multiple examples of plane frame structures and space frame structures, which lays the foundation for the analysis of practical engineering projects.

Due to the complexity and diversity of engineering projects and the release of new specifications of China, higher requirements of structural design were put forward, and continuous collapse resistance analysis of the structure 
has become an effective approach to examine the rationality and stability of the whole structure to provide the basis for structural safety evaluation thus effectively reduce or even avoid such accidents.

In this paper, based on a high-rise frame-core tube practical project, the dynamic response and damage degree of the structure with key member removed were analyzed by numerical simulation method and large-scaled collapse tests to verify that this project has a good progressive collapse resistance under incidental loads.

\section{Engineering Situation}

This project is located in Haizhu District of Guangzhou, including a commercial podium and a high-rise office building which are separated by seismic joints. The main building covers an area of $95,385 \mathrm{~m} 2$, and is $198.9 \mathrm{~m}$ high (B level height) with 43 floors on the ground and 3 floors underground, as shown in Fig. 1. And the plane size of the main building is $47.5 \mathrm{~m} \times 47.5 \mathrm{~m}$.

Based on the specifications and regulations of China, RC frame-core tube was adopted as structure system, and the main features of the structure are as follows:

1) The height of the main building is nearly $200 \mathrm{~m}$ which exceeds the appropriate maximum height of buildings.

2) The structure belongs to super high-rise buildings with several irregularities, characterized by torsion irregular and floor slab discontinuity.

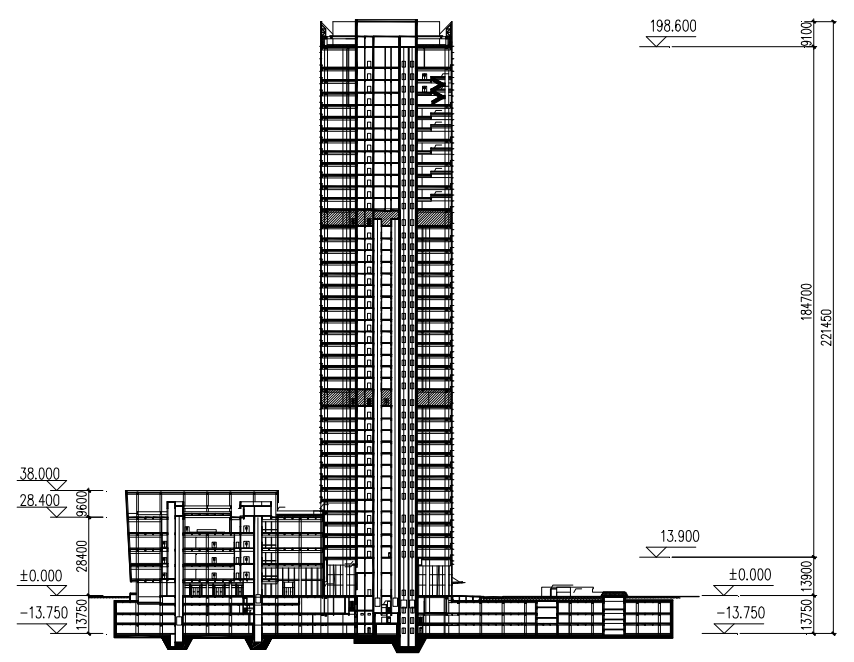

Figure 1. Architectural section.

Due to the height and huge volume of this project, the security problem was especially considered during the structure design. And taking into account that local damages and failures of outer frame components in frame-core tube structures may occur and further lead to the transmission route change of vertical loads in the unexpected events and disasters, progressive collapse analysis of this project was focus on the dynamic response of the structure with the failure of the bottom corner column under the representative value of gravity load.

Based on the studies results of progressive collapse analysis of RC structures, numerical simulation and test methods were adopted respectively to study the continuous collapse resistance of the main structure.

\section{Numerical Simulation Analysis and Main Results}

\subsection{Simulation Principle}

As a complex numerical process of gradual translation from the elastic continuum to plastomer or even non-continuum in principle, collapse simulation raises high requirements for the selections of several aspects such as collapse analysis method, numerical simulation method, and numerical simulation algorithm, and the simulation principles used in this paper are as follows.

\subsubsection{Collapse Analysis Method}

Refer to design processes and suggestions of specifications such as GSA2003, DoD2010 and JGJ3-2010 [7-9], the alternate path method with clear principle and strong operability was chosen, which is to establish the finite element model of the complete structure and then "kill" a key member to analyze the dynamic response of the remain structure. And the key members such as corner columns, middle columns at long side or short side and columns where the geometry of structure plan is obviously changed which are usually identified as the important vertical members in the force transmission system of the structure could be selected as the removed member [10-11].

\subsubsection{Numerical Simulation Method}

Considering the applicability of multi structure systems and completeness of calculation process files and large amount of applications in practical engineering [10-12], finite element method was chosen as the analysis method.

\subsubsection{Numerical Simulation Algorithm}

As the structural collapse process is always accompanied by serious nonlinear problems such as large displacement, large strain, large rotation and material nonlinearity, the explicit dynamics algorithm based on central difference method with the advantages of small step size, stability and better convergence performance was chosen to capture the internal stress wave propagation in small time steps.

\subsection{Collapse Analysis}

Based on these simulation principles, ANSYS/LS-DYNA software based on the explicit dynamics was chosen for the collapse simulation analysis. The model contains 40027 nodes, 24394 beam elements and 36364 shell elements, and the elements were joined by common node connection. In order to simulate the destruction of RC members, strength criterion and deformation criterion were mainly used as failure judgment criterion. The plastic kinematic material model was used with the parameters set as follows:

1) The equivalent yield strength value of beams and 
columns were set considering the reinforcement ratio of members which he reinforcement was converted to equivalent concrete.

2) The member was considered as failure when the tensile rate of the reinforcement steel bar was more than $10 \%$, that is, the failure of the members was controlled by effective strain.

To analysis the static and dynamic response of the frame-cure tube structure with member losing under accidental load, corner columns at one side of the main structure from the first floor to the third floor were removed to analysis the remain structure as shown in Fig. 2.

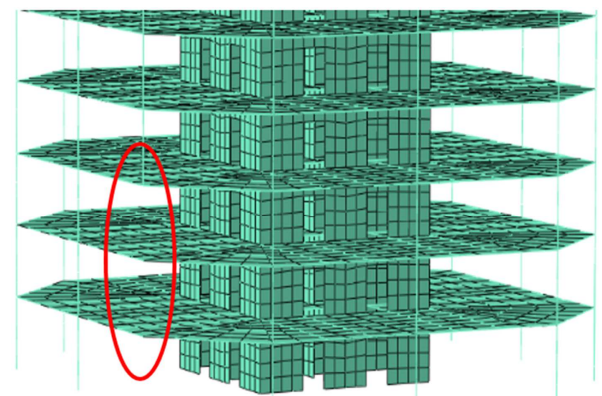

Figure 2. Numerical model with corner column removed.

\subsection{Analysis Results}

The first five natural vibration frequencies and periods of the complete model are shown in Table 1, and the vibration models are obtained as shown in Fig. 3.

Acceleration time-histories of three natural seismic waves as input: El Centro, Taft and Chi-Chi were chosen, and the horizontal peak acceleration of the primary direction was set as $310 \mathrm{~cm} / \mathrm{s}^{2}$ and the secondary direction as $263.5 \mathrm{~cm} / \mathrm{s}^{2}$ in accordance with the requirements of IV class site and 7 degree rare earthquake intensity in the "Code for Design of Concrete Structures" [13], namely the acceleration amplitude ratio of two horizontal directions is 1:0.85.

Table 1. Structural dynamic characteristics.

\begin{tabular}{lll}
\hline Modal & Frequency/Hz & Period/s \\
\hline 1 & 0.238 & 4.2012 \\
2 & 0.238 & 4.2012 \\
3 & 0.6415 & 1.5588 \\
4 & 1.0705 & 0.9341 \\
5 & 1.0706 & 0.9341 \\
\hline
\end{tabular}

Under the bi-directional seismic actions of 7 degree rare earthquake intensity, responses of the complete model and the corner column removed model of the main structure were analyzed respectively. The maximum story drift and the acceleration peak of each floor were calculated and compared, and the results are as follows:

1) Under the earthquake actions, the main structure had a good seismic performance as the maximum story drift of the nonlinear model with corner columns removed was nearly $1 / 200$ which was less than the specification limit of $1 / 100$.

2) Although the distribution laws of the story drift varied under different seismic wave input, most of the maximum story drifts appeared in the middle-upper part of the structure.

3) Removing of the corner columns had a little negative influence on the displacement response of the structure as the maximum story drift was increased by only $3 \% \sim 5 \%$ compared to the complete model, while the acceleration peak distribution was affected greatly as the acceleration peak was nearly doubled in some layers.

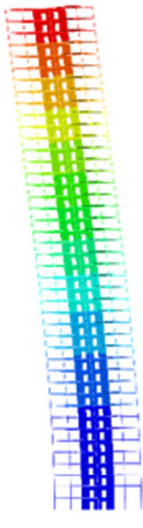

lst

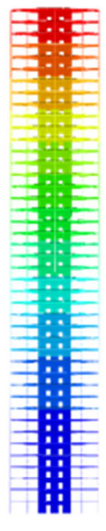

2nd

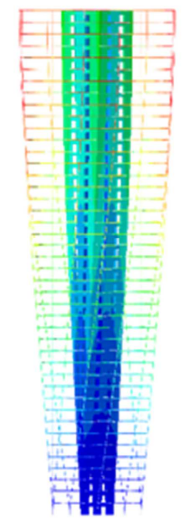

$3 r d$

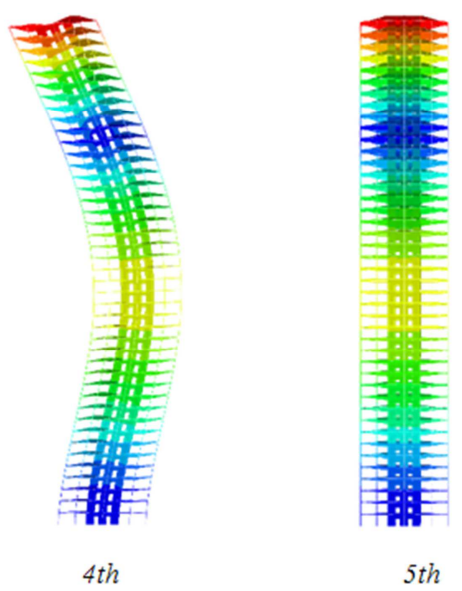

Figure 3. The first five vibration models.

In addition, the deformation of the whole structure and plastic strain of the vertical members of the two models were analyzed, and the deformation comparison in the Chi-Chi wave condition is shown in Table 2 . The results show that after removing corner columns, the whole structure was inclined to a certain, while the members' removal had a little influence on the horizontal displacement response as a whole. The plastic degree of the concrete shear wall at the column removed side was deepened and the damage scope was enlarged under the dynamic actions, which reflected that failure of the key member affected the damage accumulation process. Progressive collapse did not appear during the loading procedure, which indicates that the main structure would not collapse during the dynamic actions under 7 degree rare earthquake intensity when bottom corner column were removed, and it could be determined that the structure had a good continuous collapse resistance under this situation according to the numerical analysis. 
Table 2. Deformation and internal force comparison under 7 degree rare earthquake intensity of Chi-Chi wave.

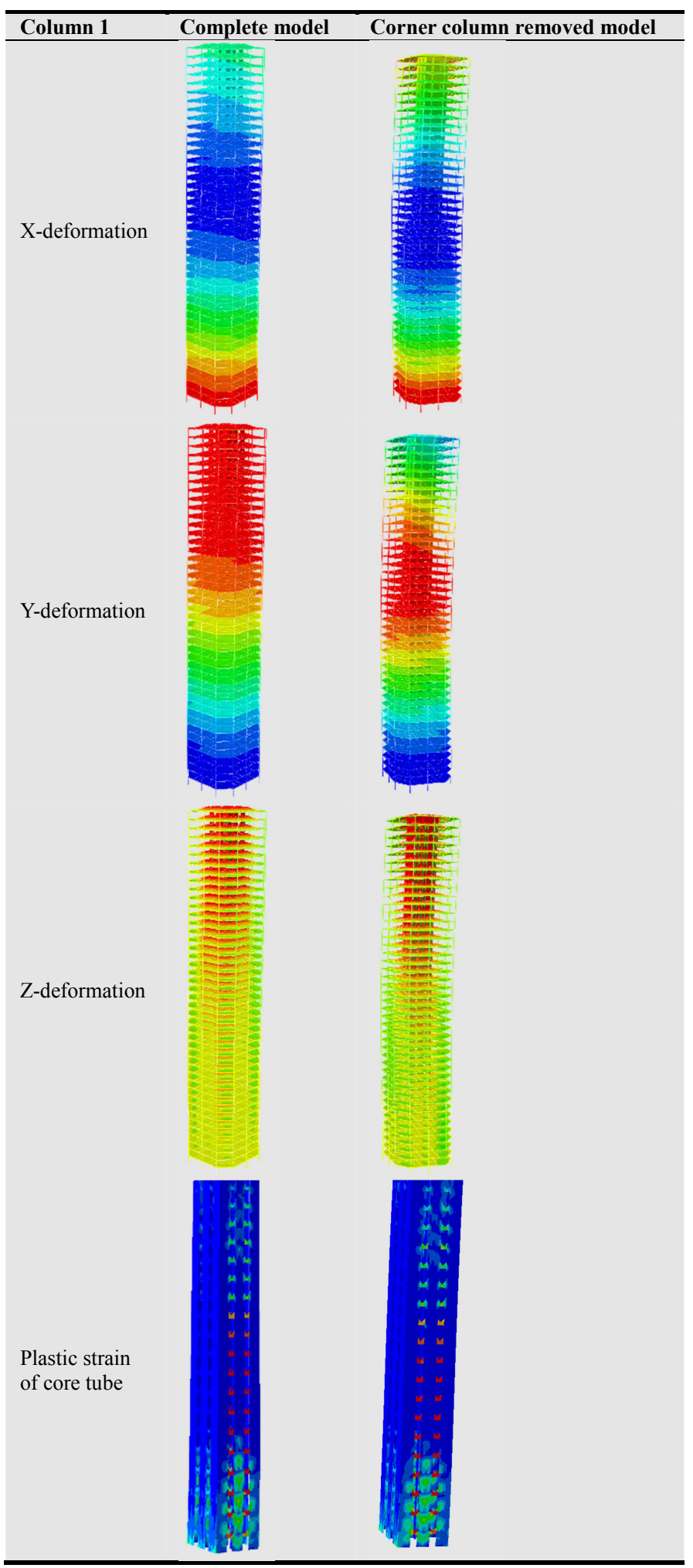

\section{Test Study and Results Comparison}

For further study of the continuous collapse resistance of frame-cure tube structure, the static test and the dynamic test were conducted respectively [14]. And Taking consideration of the size and load capacity of the shaking table in Tongji
University, the simplified model was proposed from the main structure of the practical engineering, and a $1 / 15$ scaled 7-floor test model was established based on the similarity theory. The removed column was replaced by a jack for the simulation of column failure during the static test study, and the test model is shown in Fig. 4.

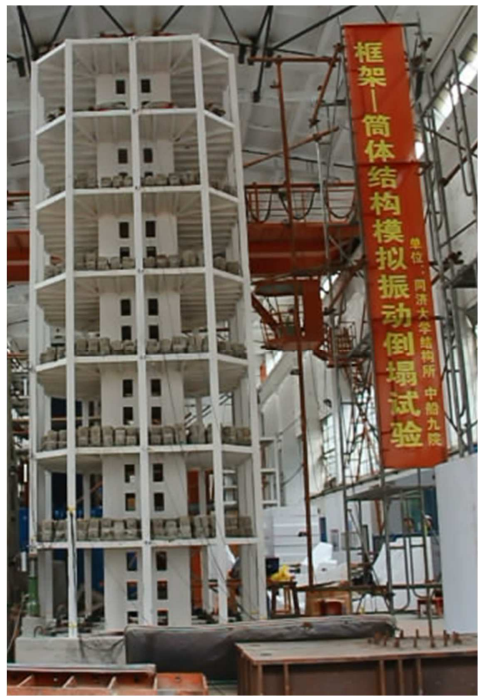

Figure 4. Test model.

During the static test condition, the jack was unloaded slowly to simulate the failure process of the bottom corner column, and the progressive collapse did not happen after the deformation of the structure achieved stability as shown in Fig. 5, which proves that the failure of the corner column would not lead to the structure progressive collapse under gravity loads.

The shaking table test was performed in situ after the static test, 5 seismic waves as EL Centro, Taft, Wenchuan, Chi-Chi and SHW01 were chosen for bi-directional and three-directional input by stage of frequent earthquake, basic earthquake and rare earthquake of 7 degree intensity, as the working conditions are listed in Table 3 .

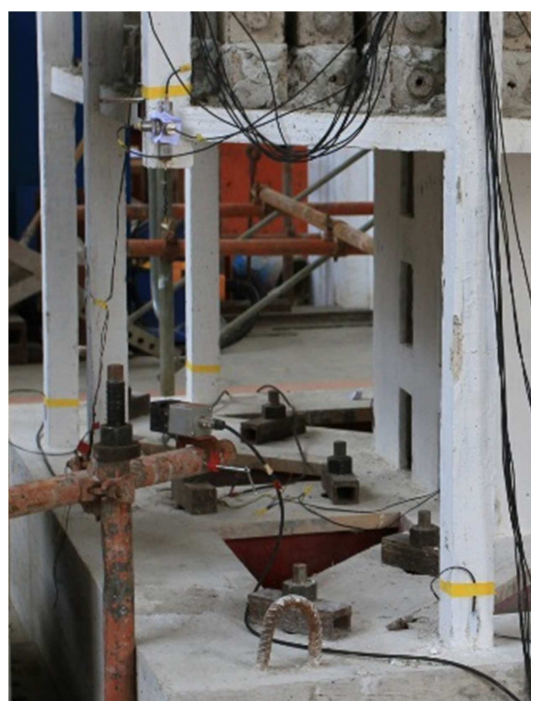

Figure 5. Static test study. 
Table 3. Structural dynamic characteristics.

\begin{tabular}{llll}
\hline Earthquake level & $\begin{array}{l}\text { Frequent } \\
\text { earthquake }\end{array}$ & $\begin{array}{l}\text { Basic } \\
\text { earthquake }\end{array}$ & $\begin{array}{l}\text { Rare } \\
\text { earthquake }\end{array}$ \\
\hline White noise & 1 & 12 & 23 \\
El Centro & 2,3 & 13,14 & 24,25 \\
Tafe & 4,5 & 15,16 & 26,27 \\
Wenchuan & 6,7 & 17,18 & 28,29 \\
Chi-Chi & 8,9 & 19,20 & 30,31 \\
SHW01 & 10,11 & 21,22 & 32,33 \\
\hline
\end{tabular}

After the frequent earthquake stage, no crake was appeared on the model and the natural frequencies of vibration were almost the same to the value before this stage, which proves that the structure with one corner column removed could still remain in flexible working stage under the seismic action of frequent earthquakes.

During the basic earthquake stage, a few vertical crakes mainly appeared at the bottom wall, and inclined crakes appeared at the end of coupling beams. As one corner column was removed, the damage degree of the shear wall adjacent to this position was higher than other shear walls.

Until the $7^{\text {th }}$ input at the rare earthquake stage, crakes on the bottom vertical supporting members developed further as shown in Fig. 6, while the whole structure did not collapse with the story drift below the specification limit of $1 / 100$, which indicates that the structure still has a certain seismic capacity.

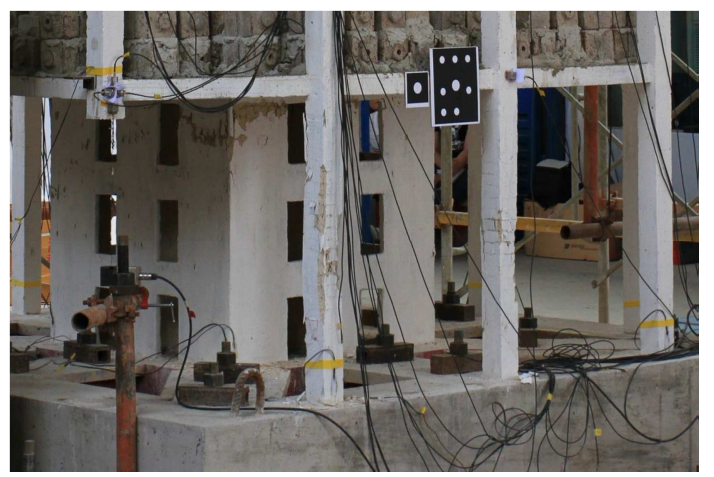

Figure 6. Damage of bottom structure under $7^{\text {th }}$ input at rare earthquake stage.

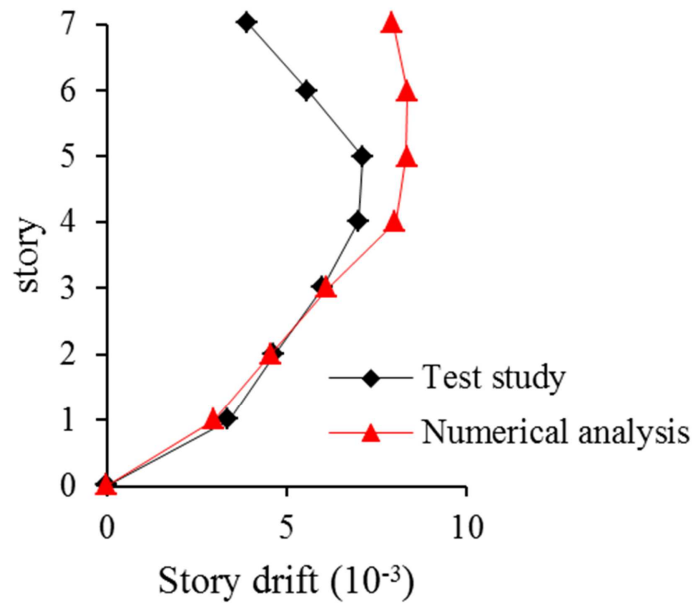

(a) X-direction

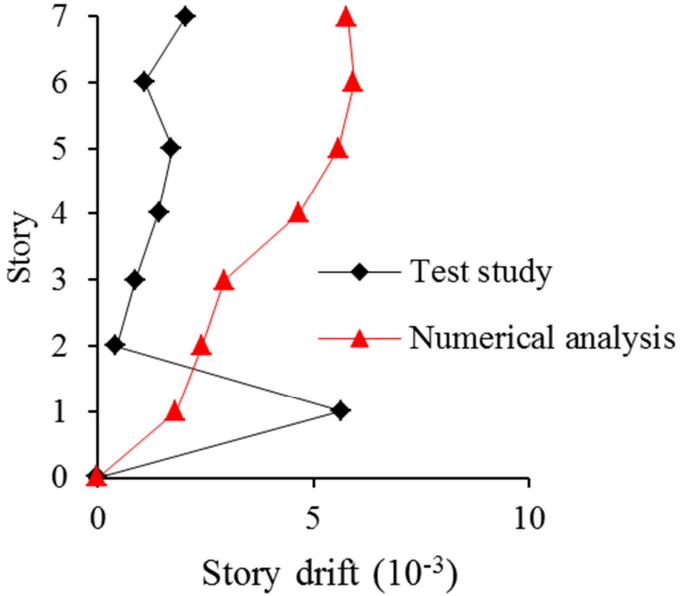

(b) Y-direction

Figure 7. Story drift comparison in 7 degree rare earthquake intensity condition.

In addition, the simulation results fit well with the test result as shown in Fig. 7, which proves that the numerical simulation method could reflect the dynamic response of the structure with local damage under seismic actions. Finally, the structure collapsed with the accumulation of damage and the further damage of the vertical components. And the bottom shear walls and key joints of the main structure were reinforced according to the results.

\section{Conclusion}

In this paper, progressive collapse resistance of a high-rise frame-core tube project was analyzed by numerical simulation based on the alternate path method and explicit dynamics to study the dynamic response of the whole structure with key members removed. And in order to verify the accuracy of the numerical simulation results, a large scaled test was performed to study the behavior of the frame-core tube structure under static and dynamic loads. The results are as follows:

1) Loss of bottom corner column has a little influence on the displacement response of the structure while the acceleration peak distribution was affected greatly, and plastic degree of the vertical members especially the concrete of the bottom shear-wall was deepened and damage scope was enlarged. With the damage accumulation of the vertical members, overall collapse would happen according to the shaking table test results. And based on the numerical simulation and test study results, the bottom shear walls and key joints of the main structure were reinforce.

2) Under the seismic action of 7 degree rare earthquake intensity, the main structure has a good seismic performance even though the bottom corner column was removed, which checked the security and ability to resist progressive collapse of the structure in this kind of incidental accident and indicated that the structure could meet the seismic fortification target of No Collapsing in the Strong Earthquake. 
3) Compared with the test and numerical simulation results, the adopted numerical method could accurately simulate the nonlinear behavior of the structure with local damage under seismic actions, which could provide the basis for continuous collapse resistance analysis of practical engineering. And through the progressive collapse analysis as one of the performance-based analyses, the structure could be more reasonable, reliable and economical.

\section{References}

[1] He Qingfeng, Research on Progressive Collapse Behavior of RC Frame Structures. Hunan University: 2009, pp. 19-37.

[2] Ma Gao, Li Hui, OU Jinping, "Dynamic response and progressive collapse resistance of RC frame structures subjected to element removal," Technology for Earthquake Disaster Prevention, vol. 5, pp. 62-72, 2010.

[3] Wang Debin, Li Hongnan, Zhang Jie, "Response analysis of $\mathrm{RC}$ frame structures in progressive collapse after the member failure," Chinese Journal of Applied Mechanics, vol. 31, pp. 116-121, 2014.

[4] He Qingfeng, Yi Weijian, "Experimental study of the collapse-resistant behavior of RC beam-column sub-structures considering catenary action," China Civil Engineering Journal, vol. 44, pp. 52-59, 2011

[5] Xiong Jingang, Wu Zhaoqiang, He Yinong, etc, "Experimental research on progressive collapse performance of RC spatial frame structures," Journal of Nanchang University (Engineering \& Technology), vol. 34, pp. 229-238, 2012.
[6] Lu Xinzheng, Lin Xuchuan, Ye Lieping, et al, "Numerical models for earthquake induced progressive collapse of high-rise buildings," Engineering Mechanics, vol. 27, pp. 64-70, 2010.

[7] Liang Yi, Lu Xin Zheng, Li Yi, etc, "Verification and analysis on foreign progressive-collapse-resistance design methods of RC frame structures," Building Structure, vol. 40, pp. 8-12, 2010 .

[8] Lu Xinzheng, Li Yi, Ye Lieping, Theory and Design Method for Progressive Collapse Prevention of Concrete Structures. Beijing: China Architecture \& Building Press, 2011.

[9] JGJ3-2010 Technical Specification for Concrete Structure of Tall Building. Beijing: China Architecture \& Building Press, 2010 .

[10] Liu Chengqing, Chen Linya, Su Qiwang. "Research on the progressive collapse resistance performance of Pengshan gymnasium," Steel Construction, vol. 30, pp. 1-5, 2015.

[11] Wei Yong, "Design of multi-story height steel cantilever truss for Handan culture and art center," Progress in Steel Building Structures, vol. 18, pp. 44-54, 2016.

[12] Sun Jian. Progressive Collapse Analysis on the Suspension Structure of Tianjing Large Theatrer Building and the Steel Structure of Tianjing Library. Tianjing University: 2012.

[13] GB50011-2010 Code for Seismic Design of Buildings. Beijing: China Architecture \& Building Press, 2010.

[14] Wang Peng, Lu Xilin, Yang Zi, et al, "Shaking Table Test Study of Earthquake Collapse of a Reinforced Concrete Frame-core Tube Structure," Structural Engineers, vol. 30, pp. 122-129, 2014. 